\title{
O2O E-commerce Mode and Its Development Prospect
}

\author{
- A Case Study based on Suning Cloud Commerce
}

\author{
Hui Zhang \\ Sichuan Technology and Business University, Chengdu City, Sichuan \\ Province, 610000, China
}

\begin{abstract}
With the coming of the mobile Internet era, the integration of online and offline gradually appears, and $\mathrm{O} 2 \mathrm{O}$ mode has been an irresistible trend. In this paper, the $\mathrm{O} 2 \mathrm{O}$ E-commerce mode and its development prospect were analyzed by taking Suning cloud commerce for example. Based on the author's learning and practical experience, we initially analyzed the application of O2O model in Suning cloud commerce, and then the advantages and disadvantages of the $\mathrm{O} 2 \mathrm{O}$ model were revealed. Finally, the development prospect of $\mathrm{O} 2 \mathrm{O}$ business mode was pointed out.

Keywords: O2O; Suning cloud commerce; E-commerce; development prospect
\end{abstract}

\section{Introduction}

Presently, E-commerce is rapidly developing, whose spread depth and breadth are far beyond people's imagination. E-commerce has many modes such as B2B, B2C, B2G, C2C and so on, in which B2C (Business To Customer) mode is much more common. Simply speaking, this mode is that the enterprises deliver goods to the customers through the way of logistics distribution such as the express. Typical examples are Taobao, Jingdong, Vipshop and the like[1]. O2O is the abbreviation of Online To Offline, and this concept appeared later than B2C and C2C. Its development prospect was found by the public until the United States Groupon was listed in public. A batch of enterprises with $\mathrm{O} 2 \mathrm{O}$ modes arise worldwide since then. 


\section{Application of $\mathrm{O2O}$ Mode in Suning Commerce}

Since 2011, Suning has persistently performed the ten-year development strategy named "technological transformation and intelligent service", and gradually explored a business form characterized by online and offline multi-channel integration, the whole category management, and open platform services. In this manner, the cloud service mode was further deepened. After business accumulation in several years, Suning has built up a management cloud for internal staff, a supply-oriented cloud for supplier, and a consumer-oriented cloud for consumers[2]. Additionally, she has gradually promoted a comprehensive market-oriented operation with the "cloud service" mode, and successively launched Suning Enjoy Your Life, cloud application store, cloud reading and so on. Suning holds that its future retail model is "store commerce + electronic commerce + retail service commerce, which was called "cloud commerce" mode. At the beginning of 2014, along with the vigorous development of the Internet economy, and the complexity and variability of consumption economy form, the traditional industries are aging and deficient in innovation, and retailers attempt to achieve self-salvation via $\mathrm{O} 2 \mathrm{O}$, which have their own ways in the process of looking for differentiation. Following the opening of Suning cloud platform and offline super-store settlement, Suning has conducted large-scale organizational restructuring once again, and established Internet-enabled senior management team. Currently, when the E-commerce giants Tmall, Jingdong actively begin to combine with many entity retailers, bring forth innovative payment methods, and carry out joint marketing, the traditional retail giant Suning is already skillful in $\mathrm{O} 2 \mathrm{O}$ exploration, which starts from the air conditioner retail, then the national chain, and finally the current Internet operation. It is not difficult to find out that Suning is exploring a way of online and offline integration via online and offline channels in the process of transformation.

In 2014, the strategy of Suning is a breakthrough of online management pattern in the super-size cities in China, and the $\mathrm{O} 2 \mathrm{O}$ integration of the third and fourth markets. Suning Group established operational headquarter through integrating the chain operational headquarter responsible for offline entity stores operation with the E-commerce operational headquarter responsible for online Suning Tesco management. In addition, Suning logistics has an increasingly important strategic position[3]. On the one hand, Suning announced the establishment of an independent logistics company. On the other hand, Suning realized the uniform integration of multi-entrance layout at store port, PC port, mobile phone port and TV port, in which the operation headquarter was split into mobile shopping and home Internet business departments. Suning will accelerate the development of these two parts. Obviously, the logistics strategic position increases rapidly, which could promote the $\mathrm{O} 2 \mathrm{O}$ integration. There is no doubt that Suning needs to combine the Internet thought with the retail practice. The implementation of the Internet age should not be a standard copy. The retailers also need to strengthen the "Omni-Channel" sales. For example, on one side, Suning is landing "cloud shop" physical store to enlarge the expansion speed of maternal and child brand namely Red Children, and conducting the practice of $\mathrm{O} 2 \mathrm{O}$ mode in the category 
expansion. On the other side, she achieves life localization and service platform exploitation through mergers and acquisitions.

\section{Advantages and Disadvantages of O2O Mode}

\subsection{Advantages of $\mathrm{O} 2 \mathrm{O}$ mode}

First, the $\mathrm{O} 2 \mathrm{O}$ mode attributes to getting more publicity and exhibition opportunities to attract more new customers to consume, which is more efficient for stimulating the consumption of new products and stores. More display and promotion opportunities can be provided to the stores through the $\mathrm{O} 2 \mathrm{O}$ website. Compared with the way of publicity including advertising and printing leaflets usually used by the stores in the traditional media, $\mathrm{O} 2 \mathrm{O}$ website is undoubtedly a cost-effective marketing channel[4].

Second, the promotion effect can be investigated, and each transaction can be tracked. The consumers take online orders at the $\mathrm{O} 2 \mathrm{O}$ website, and then get to the physical stores to consume. In this way, the effect of online promotion can be directly observed by the stores.

Third, the user data can be tracked, and accurate impact can be carried out. From a perspective of customer relationship management, having richer customer data is a prerequisite for successful product or service delivery. This is an important reason for cooperation of the physical stores with the $\mathrm{O} 2 \mathrm{O}$ website. On the one hand, grasping the user data can greatly enhance the maintenance and marketing effect of old customers. On the other hand, the user's communication and doubtresolving attributes to better understanding of the user's psychology.

Fourth, the operation can be reasonably arranged and the cost can be saved through effective online reservation. Fifth, the $\mathrm{O} 2 \mathrm{O}$ mode can reduce the dependence of offline entity on the Mong shops at the prime site, which greatly decreases rental expenses. For the physical store, as the flow of people is different, the impact of location on the store is usually significant. If the information such as discount and promotion delivered at the $\mathrm{O} 2 \mathrm{O}$ website can attract the visitors to consume, and its location is detailed, the consumer can take the initiative to find the store. Even if the location of the shop is relatively remote, the influence is negligible.

\subsection{Disadvantages of $\mathrm{O} 2 \mathrm{O}$ model}

First, homogeneous products on the website have serious homogeneity competition. Second, compared with the self-built B2C website, the online time of publicity information is enslaved to $\mathrm{O} 2 \mathrm{O}$ website, and the online continuity is not strong. Third, the loyalty degree of the users is low. 


\section{Development Prospect of O2O Business Mode}

\subsection{Establishment of the credit system}

The issues such as business qualification and integrity must be resolved to develop $\mathrm{O} 2 \mathrm{O}$. On the one hand, the business management qualifications and behaviors can be checked to restrain their behaviors via the cooperation with local business sector or consumer association. On the other hand, we should establish a sound integrity mechanism. For example, the third-party institutions can be introduced to monitor the $\mathrm{O} 2 \mathrm{O}$ operators and conduct the credit rating. The rating results should be timely delivered to the consumer. In this manner, the $\mathrm{O} 2 \mathrm{O}$ operators will be urged to maintain their reputations[5]. For the credibility of the business, we can consider a similar customer evaluation method as Taobao to rank them.

\subsection{Further subdivision of the market}

From a simple point of view, although $\mathrm{O} 2 \mathrm{O}$ is mainly related to the Internet platform, businesses and consumers, the specific consumption areas can be further subdivided. Taking group purchase for example, the various concessions and businesses on the website usually make the customers dazzled. If we want to do $\mathrm{O} 2 \mathrm{O}$ well, in addition to focusing on traditional food and small consumption areas, the more attention should be paid to some bulky consumption areas such as real estate, home furnishing, marriage, car, parent-child, education and so on. However, it should be noted that the consumers could propose higher service quality requirements for $\mathrm{O} 2 \mathrm{O}$ platform with the deepening of industry subdivision. It is not the case that the concession is bound to attract a large number of loyal users, generate the interaction, and attract them to reconsume. Active interaction and share are the highlight of $\mathrm{O} 2 \mathrm{O}$, which should not be limited to a single platform or Internet product.

\subsection{More participation of traditional industries}

O2O mode leaves the traditional industries, especially the service industry, seize the opportunity of the Internet, which are hovering out of the E-commerce. O2O brings the online consumers to the offline physical stores to consume, which focuses on the service consumption provided by the local businesses such as catering, movies, fitness, car rental, house rental and so on. Provided that online payment must be performed previously, service enterprises can take full advantage of the $\mathrm{O} 2 \mathrm{O}$ mode to actively participate in E-commerce so that more consumers can come to the stores to consume[6].

\subsection{Seize the development opportunities of the mobile commerce}

Mobile commerce refers to the mode that the mobile communication technology is considered as the support, and the business activities are performed via mobile 
digital terminals. Compared with the traditional E-commerce, mobile commerce has its unique advantages.

The first advantage is the widespread existence. The users of the mobile commerce could continuously change their positions and are in the mobile state. As long as there is a mobile phone signal, the consumers can conduct Ecommerce activities without the time and place restrictions.

The second one is good personalized experience. Generally, the mobile terminals used by the service object are personal mobile phone. The consumers can customize the required services and information according to their needs and preferences, which can fully meet the users' expectations.

The third one is portability. The user's mobile terminal is very easy to carry, and the mobile payment is characterized by convenience, low cost and simple operation. It can be said that the mobile business is the main development direction in future, and the mobile applications are the new trends in the process of E-commerce development in future.

Mobile $\mathrm{O} 2 \mathrm{O}$ is based on the mobile Internet, and performs the identification through the users' identity and the consumers' discount credentials, which can achieve efficient, interactive and localized services. Mobile Internet has an evident advantages of huge users' base, and closer markets and consumers[7].

Mobile commerce will become the driving force for the $\mathrm{O} 2 \mathrm{O}$ mode, which can be integrated into the broader business world. Many businesses stationed in the open platform can quickly and easily deploy personalized experience, provide consumers with preferential vouchers, attract consumers to the store to consume, and obtain a real return.

\subsection{Explore a better profit mode}

The current charge mode of $\mathrm{O} 2 \mathrm{O}$ platform to the business is mainly based on advertising. If we can make the business pay according to the effect of consumption, and provide accurate value-added services for them, it will undoubtedly better meet the demands of businesses and can also increase the enthusiasm of businesses, which attributes to forming a virtuous circle and promoting the further development of $\mathrm{O} 2 \mathrm{O}$ website. The future $\mathrm{O} 2 \mathrm{O}$ website should focus on searching for more potential and more competitive business mode. The own media advantage can help the business find out some valueadded services. The business strategy should be determined according to the specific circumstances to achieve the aim of coexistence, mutual benefit and winwin situation.

\section{Conclusion}

Currently, $\mathrm{O} 2 \mathrm{O}$ is undergoing a high-degree integration development with the local community, which is bound to integrate the local services of the Internet into large-scale one. $\mathrm{O} 2 \mathrm{O}$ mode brings not only a change in consumption thought and service mode, but also a new challenge on the traditional electric business. 
The operators should timely change the inherent thought, make use of their own accumulated network resources, conduct a great deal of data analysis, fully realize the convenience of mobile Internet, integrate the online and offline resources, obtain maximum realization of the seamless connection between information and entity, online and offline, physical store and physical store, and finally create a new and win-win business mode. It can be said that exploring the way of online and offline economic integration is the inevitable development trend of the E-commerce. Therefore, $\mathrm{O} 2 \mathrm{O}$ mode has a broad development prospect.

\section{References}

[1] SHEN Luyan. O2O business model and its development. Manager' Journal, (29), pp.301-302, 2016.

[2] RUAN Jing. Analysis on the application of $\mathrm{O} 2 \mathrm{O}$ business model. Chinese\&Foreign Entrepreneurs, (04), pp.119-120, 2016.

[3] LI Haolin. O2O Mode-based on bibliometric analysis. Modern Economic Information, (03), pp.115-116,2015.

[4] PENG Hui, WU Li. O2O E-commerce: power, patterns and prospects. Journal of South China University of Technology (Social Science Edition), (06), pp.10$17,2014$.

[5] ZHANG Rongqi, TIAN Wenli. Study on the business model of O2O chain in catering chain. China Market, (32), pp.81-88,2014.

[6] GE Yizhong. Applying strategy of $\mathrm{O} 2 \mathrm{O}$ business model in apparel retail. Cooperative Economy\&Science, (14), pp.77-78, 2014.

[7] LU Yiqing, LI Chen. O2O Business model and its development. Enterprise Economy, (11), pp.98-101, 2013. 